\title{
Analisis C, N, C/N Ratio Tanah dan Hasil Padi yang Diberi Pupuk Organik dan Pupuk Hayati Berbasis Azolla Pada Lahan Sawah Organik
}

\section{Mieke Rochimi Setiawati, Diyan Herdiyantoro, Maya Damayani, dan Pujawati Suryatmana}

${ }^{1}$ Departemen Ilmu Tanah dan Sumberdaya Lahan, Fakultas Pertanian Universitas Padjadjaran

Jl. Raya Bandung Sumedang Km 21 Jatinangor

Korespondensi: m.setiawati@unpad.ac.id

\begin{abstract}
Organic farming, especially organic rice requires a continuing supply of organic fertilizer in large quantity as a source of nutrition for rice plants. In long-run, organic system is can retain higher soil organic carbon (SOC), partially compensates the negative impact by improving physical and biological properties, as well as nutrient retention capacity of the soil. Azolla pinnata is an organic nitrogen source rich in protein. The high nitrogen content in A. pinnata is related to the presence of nitrogen-fixing Anabaena azollae microsimbion in A. pinnata leaves. A. pinnata compost is an alternative for biofertilizer carrier that can be used in organic rice fields. The contribution of azolla-based organic farming for organic farmers is to decrease the dependency on the animal manure in cropping season. The field experiment comprised of conventional compost as control and combination of organic fertilizer and biofertilizer with Azolla carrier. Organic fertilizer were 5 ton/hectare (ton/ha), 7.5 ton/ha, and 10 ton/ha combined with $0,10,20 \mathrm{~kg} / \mathrm{ha}$ biofertilizer with Azolla carrier with no addition of inorganic fertilizer. Complete randomized design were used in the experiment which consisted of three replications. This technology produced organic fertilizer better than conventional compost of rice straw and manure made by farmers. Organic fertilizer base with Azolla mixture of 7.5 ton ha ${ }^{-1}$ plus solid biofertilizer $(10 \mathrm{~kg} / \mathrm{ha}$ ) can produce 6.58 ton/ha of dry harvested grain, higher than conventional compost treatment (control). The application of organic fertilizer base on azolla and solid biofertilizers gave the increasing yield prospect of organic rice in Cisayong, Tasikmalaya regency West Java.
\end{abstract}

Keywords : Azolla pinata, carbon, nitrogen, organic farming, rice.

\section{PENDAHULUAN}

Pupuk merupakan sumber hara yang berfungsi sebagai input yang menentukan kinerja tanaman sebagai mesin biologis agar dapat berproduksi dengan optimal. Pemupukan merupakan suatu tindakan pemberian unsur hara sebagai sumber nutrisi pada saat masa pertumbuhan dan perkembangan tanaman agar didapat produksi sesuai dengan yang diharapkan dan dapat menjaga produktivitas tanah. Pupuk dan pemupukan dapat dilakukan dengan aplikasi bahan organik dan inorganic pada tanah.

Bahan organik yang terkandung dalam pupuk organik berfungsi sebagai sumber nutrien, menunjang ketersediaan nutrien dan kehidupan jasad mikro di dalam tanah (Sulistiono, dkk., 1992). Bahan organik yang diberikan ke dalam tanah dan terdekomposisi secara sempurna dapat menyediakan unsur hara yang lebih mudah diserap oleh tanaman.
Beberapa zat pengatur tumbuh dan vitamin diserap oleh tanaman sehingga dapat merangsang pertumbuhan (Rahmawati, 2005).

Selain menjaga kelestarian alam, pupuk organik menyediakan unsur hara makro Nitrogen (N), Fosfor (P), Kalium (K), Natrium (Na), Kalsium (Ca), Magnesium (Mg) dan Sulfur (S), serta mengandung unsur hara mikro besi $(\mathrm{Fe})$, mangan $(\mathrm{Mn})$, seng $(\mathrm{Zn})$, tembaga $(\mathrm{Cu})$, molibdenum (Mo), boron (B), dan klor (Cl) (Wiharto, 2005). Keunggulan pupuk organik yaitu tidak mempunyai residu bagi tanah dan dapat memperbaiki sifat fisik tanah sehingga meningkatkan kesuburan tanah, sedangkan kelemahan pupuk organik yaitu dapat menjadi faktor pembawa penyakit, respons tanaman lambat, unsur hara cenderung lebih rendah dibandingkan dengan pupuk anorganik (Ismawati, 2006).

Penambahan bahan organik dapat berpengaruh terhadap $\mathrm{pH}$ tanah dapat 
meningkatkan atau menurunkan tergantung oleh tingkat kematangan bahan organik yang ditambahkan dan jenis tanahnya. Ketersediaan bahan organik juga dapat memudahkan tanaman dalam penyerapan unsur hara. Padi dapat berproduksi secara optimal di lahan yang mengandung banyak bahan organik (Andoko, 2002). Bahan organik tanah terdiri dari humus, yang merupakan hasil dari dekomposisi bahan segar dan sisa jaringan resisten pada mikroorganisme yang terdekomposisi. Bahan organik, secara umum mempunyai populasi mikroorganisme tinggi yang akan memacu aktivitas mikroorganisme dalam tanah (Sukartaatmadja, 2004). Bahan organik yang dapat digunakan antara lain adalah tanaman paku air azolla.

Azolla adalah tanaman paku air yang banyak tumbuh permukaan air sawah. Azolla dapat digunakan sebagai pupuk hijau yang mengandung $\mathrm{N}$ tinggi karena bersimbiosis dengan sianobakteria penambat N. Dengan cara dikomposkan azolla akan menyediakan unsur nitrogen, fosfor, sulfur dan unsur hara lainnya bagi tanaman. Azolla dapat dimanfaatkan sebagai bahan campuran kompos jerami yang merupakan limbah panen padi sehingga dapat mempertahankan kesuburan tanah melalui nutrisi yang diberikan oleh bahan organik.

Azolla yang tumbuh pada tanaman padi dapat berperan sebagai sumber bahan organic dan agen dalam menekan pertumbuhan gulma (Sebayang, 1996). Azolla memiliki kandungan $\mathrm{N}: 3,91 \%, \mathrm{P}: 0,30 \%, \mathrm{~K}: 0,65 \%, \mathrm{C} / \mathrm{N}: 6$ dan bahan organik 39,905. Kemampuan bahan organik untuk melepaskan unsur hara tergantung dari nilai $\mathrm{C} / \mathrm{N}$ ratio. Semakin rendah nilai $\mathrm{C} / \mathrm{N}$ ratio maka akan semakin mudah untuk melepaskan unsur hara.

Pupuk hayati menurut SK Menteri Pertanian No.70/Permentan/SR.140/10/ 2011 adalah produk biologi aktif terdiri atas mikroba yang dapat meningkatkan efisiensi pemupukan, kesuburan, dan kesehatan tanah. Pupuk hayati menghasilkan nutrisi tanaman seperti nitrogen dan fosfor melalui kegiatan dalam tanah atau rizosfir dan membuat tersedia bagi tanaman secara bertahap.

Penggunaan pupuk hayati bertujuan untuk meningkatkan jumlah mikroorganisme dan mempercepat proses mikrobiologis untuk meningkatkan ketersediaan hara, sehingga dapat dimanfaatkan oleh tanaman. Mikroorganisme tersebut bermanfaat untuk mengaktifkan serapan hara oleh tanaman, menekan soil-bone disease, mempercepat proses pengomposan, memperbaiki struktur tanah, dan menghasilkan substansi aktif yang dapat meningkatkan pertumbuhan tanaman.

Bakteri pemfiksasi nitrogen non simbiotik diantaranya Azotobacter dan Azospirillum. Spesies Azospirillum brasilense dapat menambat nitrogen bebas pada medium agar dalam kondisi anaerob maupun dalam medium cair bebas nitrogen. Azospirillum brasilense mampu memproduksi giberelin (GA) pada reaksi biokimia yang kompleks dan interaksinya dengan mikroba lain (Janzen, 1992). Kelompok bakteri pelarut fosfat dapat melarutkan fosfat yang terikat di dalam tanah melalui produksi asam-asam organik yang memiliki kemampuan yang tinggi dalam melarutkan kalsium-fosfat anorganik. Strain Bacillus firmus memiliki kemampuan tinggi dalam melarutkan $\mathrm{P}$ dan mampu menghasilkan IAA.

Menurut Mezuan dkk (2002) pupuk hayati berpengaruh nyata terhadap jumlah anakan total dengan nilai rata-rata tertinggi sebesar 2.58 batang. Pengaruh nyata interaksi terjadi pada perlakuan pupuk hayati yang dikombinasikan dengan bahan organik terhadap jumlah anakan total. Kombinasi pupuk hayati dan bahan organik mempengaruhi sifat fisik dan biologi tanah, khususnya stabilitas agregat dan bioaktivitas tanah. Pemberian bahan organik berpengaruh nyata terhadap tinggi tanaman, jumlah anakan, bobot gabah pot ${ }^{-1}$ dan bobot 100 butir gabah.

Biomassa azolla dapat dijadikan sebagai pupuk organik sumber Nitrogen (N) yang cocok dikembangkan oleh para petani dan sangat mudah untuk diaplikasikan serta relatif 
murah karena tidak memerlukan biaya tambahan yang memberatkan petani. Azolla adalah tanaman air yang dapat berperan memfiksasi unsur $\mathrm{N}$ dari udara. Kelebihan dari Azolla dibandingkan dengan bahan organik lainnya adalah: (1) mudah tumbuh sehingga dapat diproduksi dalam waktu cepat; (2) mudah terkomposkan; (3) kandungan nutrisi lebih tinggi dibandingkan kompos lain; (4) biaya produksi rendah; (5) Meningkatkan kualitas mutu gabah; (6) dalam jangka panjang akan menguntungkan kondisi tanah menuju sistim pertanian yang berkelanjutan. (Hati, 2012).

Efisiensi pemupukan adalah hal yang penting bagi pelaku usaha pertanian mengingat tingkat kehilangan yang tinggi akibat proses - proses dalam tanah (aliran pemupukan, pencucian, evaporasi, fiksasi dan mobilisasi). Kecenderungan semakin tingginya biaya produksi pupuk urea, serta meningkatnya kesadaran manusia akan isu lingkungan, maka penggunaan pupuk sintetik secara perlahan akan diminimalkan dan ditingkatkan pada penggunaan pupuk yang ramah lingkungan bersumber dari bahan baku terbaharui seperti pupuk hayati dan pupuk organik (Saraswati, 2004).

\section{METODOLOGI}

Penelitian ini dilakukan lahan petani padi organik di sentra padi organik Cisayong Tasikmalaya, Jawa Barat. Jenis tanah lahan percobaan adalah Inseptisol dengan kandungan fraksi pasir 9\%, debu 35\%, dan liat $56 \%$ yang tergolong ke dalam tekstur liat. Karakter kimia dari tanah Inseptisol ini bersifat sedikit masam dengan $\left(\mathrm{pH} \mathrm{H}_{2} \mathrm{O}=\right.$ 6,36); kadar bahan organik rendah $(1,30 \%)$; kandungan $\mathrm{N}$ total sedang $(0,22 \%)$; kadar $\mathrm{P}_{2} \mathrm{O}_{5}$ tersedia $(49,51 \mathrm{mg} / \mathrm{kg})$ dan $\mathrm{P}$ total tinggi bertutut-turut dengan kandungan dan $(24,71$ $\mathrm{mg} / 100 \mathrm{~g}$ ); dan kadar $\mathrm{K}$ total rendah $(15,21 \mathrm{mg} / 100 \mathrm{~g})$. Kandungan kation Ca termasuk sedang $(8,95 \mathrm{cmol} / \mathrm{kg}) ; \mathrm{Na}$ sedang $(0,44 \mathrm{cmol} / \mathrm{kg})$; dan $\mathrm{Mg}$ sangat tinggi $(8,53$ $\mathrm{cmol} / \mathrm{kg}$ ); kapasitas tukar kation yang tinggi $(42,51 \mathrm{cmol} / \mathrm{kg})$.
Benih padi varietas Sintanur dikecambahkan dengan air rendaman selama 12 jam dan kemudian diinkubasi dalam kain lembab selama dua hari. Benih yang sudah berkecambah ditanam dalam campuran tanah dan kompos di atas nampan selama tujuh hari. Benih ditabur dengan jarak tanam $35 \mathrm{~cm}$.

Benih padi varietas Sintanur dikecambahkan dengan merendam di dalam air selama 12 jam dan kemudian diperam di dalam kain lembab selama dua hari. Benih kemudian dipindahkan ke dalam media campuran tanah dan kompos (1:1) yang ditempatkan pada nampan selama tujuh hari kemudia bibit tersebut ditanam lahan sawah dengan jarak tanam $35 \times 35 \mathrm{~cm}$.

Perlakuan pupuk organik berbasis Azolla diaplikasikan ke lahan sawah dengan dosis 5 , $7,5,10$ ton/ha sebagai pupuk organik seminggu sebelum tanam dikombinasikan dengan pupuk hayati padat berbasis Azolla dengan dosis 0,10 dan $20 \mathrm{~kg} / \mathrm{ha}$ yang diaplikasikan 2 kali aplikasi yaitu pada saat tanam dan 21 hari setelah tanam. Terdapat 10 perlakuan yang dapat disusun sebagai berikut:

- $\quad$ Kontrol = perlakuan petani organik

- $\mathrm{A} 1 \mathrm{H} 0=$ pupuk organik $5 \mathrm{t} / \mathrm{ha}+0 \mathrm{~kg} / \mathrm{ha}$ pupuk hayati berbasis Azolla

- $\mathrm{A} 1 \mathrm{H} 1$ = pupuk organik $5 \mathrm{t} / \mathrm{ha}+10 \mathrm{~kg} / \mathrm{ha}$ pupuk hayati berbasis Azolla

- $\mathrm{A} 1 \mathrm{H} 2=$ pupuk organik $5 \mathrm{t} / \mathrm{ha}+20 \mathrm{~kg} / \mathrm{ha}$ pupuk hayati berbasis Azolla

- $\mathrm{A} 2 \mathrm{H0}=$ pupuk organik 7,5t/ha +0 $\mathrm{kg} / \mathrm{ha}$ pupuk hayati berbasis Azolla

- $\quad$ A2H1 = pupuk organik 7,5t/ha + 10 $\mathrm{kg} / \mathrm{ha}$ pupuk hayati berbasis Azolla

- $\mathrm{A} 2 \mathrm{H} 2=$ pupuk organik $7,5 \mathrm{t} / \mathrm{ha}+20$ $\mathrm{kg} / \mathrm{ha}$ pupuk hayati berbasis Azolla

- $\mathrm{A} 3 \mathrm{H} 0=$ pupuk organik $10 \mathrm{t} / \mathrm{ha}+0 \mathrm{~kg} / \mathrm{ha}$ pupuk hayati berbasis Azolla

- A3H1= pupuk organik 10t/ha + 10 $\mathrm{kg} / \mathrm{ha}$ pupuk hayati berbasis Azolla

- $\mathrm{A} 3 \mathrm{H} 2=$ pupuk organik $10 \mathrm{t} / \mathrm{ha}+20$ $\mathrm{kg} / \mathrm{ha}$ pupuk hayati berbasis Azolla

Pupuk hayati padat dari kompos Azolla mengandung bakteri penambat nitrogen Azotobacter sp., Azospirillum sp., Bakteri 
endofit pengikat N, dan Bakteri Pelarut Fosfat. Sebagai kontrol perlakuan digunakan pemupukan kompos pupuk kandang sapi 10 ton/ha yang dilakukan petani setempat. Penyakit dan hama dikendalikan dengan menggunakan ekstrak nimba, temulawak, bawang putih, dan serai mengikuti prosedur penggunaan pestisida nabati.

Rancangan penelitian yang digunakan adalah Rancangan Acak Kelompok. Plot percobaan padi organik yang digunakan sebanyak 30 petak dengan luas petak $4 \times 5 \mathrm{~m}=$ $20 \mathrm{~m}^{2}$. Total luas lahan percobaan yang dibutuhkan seluas $600 \mathrm{~m}^{2}$. Seluruh perlakuan percobaan diulang tiga kali.

\section{HASIL DAN PEMBAHASAN}

\subsection{Kandungan C, N dan C/N Tanah Sawah Organik}

Salah satu aspek penting dari keseimbangan hara total di dalam tanah adalah nisbah C-organik dan N Total yang merupakan kandungan penting dalam tanah. Nisbah $\mathrm{C}, \mathrm{N}$ akan mempengaruhi ketersediaan unsur hara karena $\mathrm{C} / \mathrm{N}$ berbanding terbalik dengan ketersediaan unsur hara. Bila $\mathrm{C} / \mathrm{N}$ terlalu tinggi maka kandungan unsur hara sedikit tersedia untuk tanaman karena bahan organiknya belum terdekomposisi sempurna, sedangkan jika $\mathrm{C} / \mathrm{N}$ cukup rendah maka ketersediaan unsur hara tinggi dan tanaman dapat memenuhi kebutuhan hidupnya.

Kandungan $\mathrm{C}, \mathrm{N}$ dan $\mathrm{C} / \mathrm{N}$ tanah sawah pada semua perlakuan tidak menunjukkan perbedaan yang nyata. Walaupun pupuk organik berbasis azolla dalam berbagai dosis diberikan pada tanah sawah tidak menunjukkan perbedaan dibandingkan dengan perlakuan yang dilakukan petani padi organik setempat sebagai kontrol (Tabel 1).

$\begin{array}{cccc}\text { Kandungan } & \text { bahan organik } & \text { yang } \\ \text { rendah pada suatu lahan, } & \text { akan }\end{array}$
berpengaruh pada sifat fisik, kimia dan biologi tanah. Bahan organik ialah bahan yang berasal dari sisa-sisa makhluk hidup (tumbuhan atau hewan). Bahan organik merupakan salah satu komponen tanah yang penting bagi ekosistem tanah, dimana bahan organik merupakan sumber dan pengikat hara serta sebagai substrat bagi mikroba tanah (Kumolontang, 2008).

Tabel 1 Pengaruh Kombinasi pupuk organik berbasis Azolla dan Pupuk Hayati Padat berbasis Azolla terhadap Kandungan C, N dan C/N Tanah Sawah

\begin{tabular}{cccc}
\hline Perlakuan & $\begin{array}{c}\text { C Tanah } \\
(\%)\end{array}$ & $\begin{array}{c}\text { N Tanah } \\
(\%)\end{array}$ & C/N \\
\hline Kontrol & 1,79 & 0,17 & 10,52 \\
A1H0 & 1,72 & 0,16 & 10,75 \\
A1H1 & 1,74 & 0,17 & 10,23 \\
A1H2 & 1,75 & 0,21 & 8,33 \\
A2H0 & 1,77 & 0,22 & 8,42 \\
A2H1 & 1,92 & 0,23 & 8,34 \\
A2H2 & 1,93 & 0,21 & 9,19 \\
A3H0 & 1,93 & 0,21 & 9,19 \\
A3H1 & 1,98 & 0,21 & 9,43 \\
A3H2 & 1,93 & 0,22 & 8,77 \\
\hline
\end{tabular}

Keterangan: Angka yang diikuti oleh notasi huruf yang sama tidak berbeda nyata berdasarkan uji lanjut jarak berganda Duncan pada taraf nyata $5 \%$.

Karbon organik merupakan indikator untuk mengetahui seberapa banyak bahan organik yang terkandung di dalam tanah. Kandungan bahan organik dalam bentuk Corganik harus dipertahankan supaya tidak kurang dari 2\%, agar kandungan bahan organik dalam tanah tidak menurun seiring proses dekomposisi mineralisasi.

Peningkatan kandungan bahan organik berbanding lurus dengan peningkatan $\mathrm{C}$ organik. Pemberian bahan organik dapat meningkatkan $\mathrm{C}$ organik karena pelapukan bahan organik akan menghasilkan humus yang memiliki permukaan dapat mengikat unsur yang terkandung dalam pupuk, sehingga mengakibatkan hara yang berasal dari unsur $\mathrm{N}, \mathrm{P}$ dan $\mathrm{K}$ tidak mudah tercuci dan dapat diserap oleh tanaman secara optimal. Maka pemberian bahan organik diperlukan untuk memperbaiki kesuburan tanah (Winarso, 2005). 
Kandungan C tanah semua perlakuan menunjukkan hasil yang rendah yaitu dibawah $2 \%$. C organik tanah kurang dari $2 \%$ banyak terdapat pada lahan sawah dan seringkali dinamakan sebagai tanah yang sakit (Setyorini dkk, 2004). Kondisi ini disebabkan penanaman yang intensif dan semua hasil panen diangkut keluar, sedangkan untuk memperoleh produktivitas lahan yang optimal dibutuhkan kandungan $\mathrm{C}$ organik lebih dari 2,5\% atau kandungan bahan organik tanah > 4,3\%. Semakin rendah kadar bahan organik maka semakin rendah produktivitas lahan. Pemberian bahan organik ke dalam tanah menyebabkan peningkatan kandungan karbon yang berdampak kepada perbaikan produktivitas tanah, peningkatan pasokan hara bagi tanaman dan percepatan siklus nutrisi di dalam tanah.

Nitrogen total dalam tanah didapat dari dua sumber, yaitu sumber primer dan sekunder. Sumber N primer berasal dari atmosfir dalam bentuk $\mathrm{N}_{2}$, sedangkan sumber $\mathrm{N}$ sekunder berasal dari aktifitas kehidupan di dalam tanah. Nitrogen yang diperoleh dari atmosfer sangat bergantung pada keberadaan bakteri penambat $\mathrm{N}$ di dalam tanah diantaranya Rhizobium sp., Azotobacter sp., Clostridium sp., dan lain-lain dengan mengubah bentuk $\mathrm{N}_{2}$ di atmosfer menjadi $\mathrm{N}$ yang dapat digunakan oleh tanaman. Sumber $\mathrm{N}$ sekunder tanah dapat ditingkatkan dengan penambahan pupuk organik yang kaya akan kandungan nitrogen seperti azolla atau tanaman kacang-kacangan.

Kandungan $\mathrm{N}$ tanah sawah yang diberi perlakuan berkisar antara 0,16\% sampai 0.23 $\%$ yang menandakan bahwa tanah sawah tersebut termasuk kedalam kriteria rendah sampai sedang. Bahan organik yang diberikan ke dalam tanah sawah merupakan sumber $\mathrm{N}$ utama di dalam tanah. Pupuk hayati yang diaplikasikan ke dalam tanah sawah dapat meningkatkan kandungan $\mathrm{N}$ tanah karena mikroba penambat $\mathrm{N}$ yang berada di dalam pupuk hayati dapat mengikat $\mathrm{N}$ dari udara dan dirubah menjadi ammonium akibat kerja enzim nitrogenase yang terdapat di dalam sel bakteri penambat $\mathrm{N}$ seperti bakteri Azotobacter, Azospirillum,dan endofitik penambat $\mathrm{N}$.

$\mathrm{C} / \mathrm{N}$ tanah semua perlakuan berkisar antara 8,33 sampai 10,75 yang termasuk dalam kriteria rendah. Nisbah $\mathrm{C} / \mathrm{N}$ merupakan indikator yang menunjukkan tingkat dekomposisi dari bahan organik tanah. Apabila makin tinggi dekomposisinya maka makin kecil nisbah C/N-nya. Apabila nisbah $\mathrm{C} / \mathrm{N}$ lebih kecil dari 20 menunjukkan terjadinya mineralisasi $\mathrm{N}$, apabila lebih besar dari 30 maka terjadi immobilisasi $\mathrm{N}$, jika diantara $20-30$ berarti mineralisasi seimbang dengan immobilisasi (Hanafiah, 2005).

\subsection{Hasil Gabah Kering Panen}

Pupuk organik berbasis Azolla yang diaplikasikan ke sawah dengan dosis 5, 7,5, 10 ton/ha pada awal tanam dikombinasikan dengan pupuk hayati padat berbasis Azolla dengan dosis $0, \quad 10$ dan $20 \mathrm{~kg} / \mathrm{ha}$ memperlihatkan peningkatan yang nyata terhadap gabah kering panen. Setelah 12 MST hasil GKP per ubinan $\left(2 \mathrm{~m}^{2}\right)$ padi sawah dengan kombinasi perlakuan yang diberikan menunjukkan perbedaan yang nyata.

Hasil Gabah Kering panen per ubinan (2 $\mathrm{m}^{2}$ ) yang diberi pupuk organik dengan dosis 7,5 ton/ha ditambah pupuk hayati padat berbasis azolla 10 atau $20 \mathrm{~kg} /$ ha serta diberi pupuk hayati padat berbasis Azolla dengan dosis 10 ton/ha ditambah pupuk hayati padat berbasis azolla 10 atau $20 \mathrm{~kg} / \mathrm{ha}$ menghasilkan Gabah Kering Panen yang lebih tinggi daripada perlakuan yang biasa dilakukan petani padi organik (kontrol). Bila hasil ubinan dikonversikan kedalam luasan hektar maka diperoleh hasil padi berkisar dari 3,1-6,5 ton ha-1.

Hasil padi yang tinggi diperoleh dari pemberian pupuk organik ditambah pupuk hayati padat berbasis azolla. Apabila pupuk organik berbasis azolla tidak diberikan bersamaan dengan pupuk hayati padat (A3H0) maka hasilnya akan menurun 
(dibawah 4 ton ha-1 GKP). Disini peran bakteri yang menguntungkan pada pupuk hayati padat terlihat membantu menyediakan nutrisi melalui penambatan nitrogen dan penyediaan fosfat bagi tanaman padi.

Tabel 2 Pengaruh Kombinasi pupuk organik berbasis Azolla dan Pupuk Hayati Padat berbasis Azolla terhadap Gabah Kering Panen

\begin{tabular}{cc}
\hline Perlakuan & $\begin{array}{c}\text { Hasil GKP } \\
\text { (ton/hektar) }\end{array}$ \\
\hline Kontrol & $3,167 \mathrm{a}$ \\
A1H0 & $3,333 \mathrm{ab}$ \\
A1H1 & $3,500 \mathrm{ab}$ \\
A1H2 & $4.333 \mathrm{ab}$ \\
A2H0 & $4,250 \mathrm{ab}$ \\
A2H1 & $6,583 \mathrm{c}$ \\
A2H2 & $5,250 \mathrm{bc}$ \\
A3H0 & $3,250 \mathrm{a}$ \\
A3H1 & $4,917 \mathrm{ab}$ \\
A3H2 & $5,000 \mathrm{bc}$ \\
\hline
\end{tabular}

Keterangan: Angka yang diikuti oleh notasi huruf yang sama tidak berbeda nyata berdasarkan uji lanjut jarak berganda Duncan pada taraf nyata $5 \%$.

Pemberian pupuk organik 7,5 ton ha-1 ditambah pupuk hayati padat berbasis azolla $10 \mathrm{~kg} \mathrm{ha}^{-1}$ yang diberikan seminggu sebelum tanam dengan cara dicampurkan, dapat menghasilkan Gabah Kering Panen sebesar 6,583 ton ha ${ }^{-1}$ dan hasilnya lebih tinggi dibandingkan perlakuan yang biasa petani terapkan pada pertanaman padi organik. Pemberian pupuk organik dan pupuk hayati padat berbasis Azolla memberikan prospek peningkatan hasil padi organik di sentra padi organik Cisayong Kabupaten Tasikmalaya.

\section{KESIMPULAN}

Pemberian pupuk organik 7,5 ton ha- ${ }^{-1}$ ditambah pupuk hayati padat berbasis azolla $10 \mathrm{~kg} \mathrm{ha}^{-1}$ dapat menghasilkan Gabah Kering Panen sebesar 6,58 ton ha-1 Gabah Kering Panen yang lebih tinggi daripada perlakuan yang biasa dilakukan petani padi organik (kontrol). Pemberian pupuk organik dan pupuk hayati padat berbasis Azolla memberikan prospek peningkatan hasil padi organik di sentra padi organik Cisayong Kabupaten Tasikmalaya.

\section{UCAPAN TERIMAKSIH}

Terimakasih diucapakan kepada Direktorat Jenderal Pendidikan Tinggi Departemen Pendidikan Nasional yang telah membiayai penelitian ini pada program Penelitian Strategis Nasional 2017, dan mahasiswa yang membantu penelitian ini.

\section{DAFTAR PUSTAKA}

Andoko, A. (2002). Budidaya Padi Secara Organik. Jakarta: Penebar Swadaya

Hanafiah, K.A. 2005. Dasar-Dasar Ilmu Tanah. Jakarta: PT. Raja Grafindo Persada.

Janzen, H.H. 1992. Light-fraction organic matter in soils from longterm crop rotations. Soil Sci. Soc. Am. J. 56: 1799-1806.

Kumolontang, W. J. N. 2008. Seleksi bahan organik dalam peningkatan sinkronisasi $\mathrm{N}$ dan P oleh tanaman pada tanah masam. Soil Environments 6 (2): 98-102.

Mezuan, Handayani I.P., Inoriah E. 2002. Penerapan formulasi pupuk hayati untuk budidaya padi gogo. Jurnal Ilmu Pertan Indonesia 4: 27-34.

Rahmawati, N. 2005. Pemanfaatan Biofertilizer Pada Pertanian Organik. Universitas Sumatera Utara. Medan.

Saraswati, R., T. Prihatini, dan R.D. Hastuti. 2004. Teknologi Pupuk Mikroba Untuk Meningkatkan Efisiensi Pemupukan dan Keberlanjutan Sistem Produksi Padi Sawah. P. 169-189. Dalam: Fahmuddin Agus et al. (eds.) Tanah Sawah dan Teknologi Pengelolaannya. Pusat 
Penelitian dan Pengembangan

Tanah dan Agroklimat. Bogor.

Sebayang, H.T. 1996. Azolla, suatu kajian produksi dan potensinya dalam bidang pertanian. 97 (8), 45-48.

Setyorini, D., L.R. Widowati, dan S. Rochayati. 2004. Teknologi pengelolaan hara tanah sawah intensifikasi. Fahmuddin Agus et al. (eds.) Tanah Sawah dan Teknologi Pengelolaannya. Pusat Penelitian dan Pengembangan Tanah dan Agroklimat. Bogor.

Sukartaatmadja. 2004. Konservasi Tanah dan Air. IPB Press. Bogor.

Sulistiono, B. Sunardi dan Achmad Winarto. 1992. Penelitian Mendukung Peningkatan Produksi Tanaman Pangan. Balittan Pangan Malang.

Winarso, S. 2005. Kesuburan Tanah Dasar Kesehatan dan Kualitas Tanah. Gava Media, Yogyakarta. 